\title{
Conformal Efficiency Factors of Friction Pairs in Construction Machinery
}

\author{
Yuri Gustov ${ }^{1}$, and Petr.Shishkov ${ }^{2}$ \\ Moscow State University of Civil Engineering, Yaroslavskoe shosse, 26, Moscow, 129337, Russia
}

\begin{abstract}
Formulae for the efficiency factor of moving friction pairs of construction equipment are investigated in terms of their mutual adaptation (conformism) during friction and wear. As a basis, the average coefficients of sliding friction and dimensions of the reference line curves, the half-sums of their products of the worn surfaces microrelief for mating parts are taken. Coefficients of sliding friction and dimensions of reference lines were determined from the partial values of microwear and micromaterial of the normalized system of relative reference lines and convergences. Calculated values of conformal efficiency factors were compared with efficiency factors obtained from the tested dependence, as well as from the wedge operator in the dry friction mode. The research was carried out on the example of model hinges of hydraulic excavator attachments.
\end{abstract}

\section{Introduction}

The efficiency factor is the most important tribotechnical characteristic [1-3]. There are no approved design dependencies to determine it in respect to friction units of the construction machinery. Recently, the efficiency factor of worn part surfaces coupled by microtopographic indicators has been studied [4-6]. In particular, a slight discrepancy between efficiency factors of pins (40 to $41.3 \%$ ) and bushings (39.2 to $40.8 \%$ ) with average values of about $40 \%$ corresponded to the efficiency factor of the classical "wedge operator" has been found $[7,8]$.

Of scientific and applied interest is the comparison of element-wise efficiency factors determined by the microrelief indicators of each mating part with the efficiency factor of the friction pair, taking into account mutual adaptation (conformism) of rubbing elements as a result of friction and wear self-organization.

The purpose of this work is to form analytical formulae for determining the conformal efficiency factor of friction pairs.

\subsection{The targets are:}

1. Constructing normalized systems of relative reference lines and approximations of the microrelief of parts.

2. Determining partial values of microwear and micromaterial.

\footnotetext{
${ }^{1}$ Corresponding author: GustovUI@mgsu.ru

${ }^{2}$ Corresponding author: shishkov_petr@mail.ru
} 
3. Determining sliding friction coefficients of parts.

4. Determining the relative length of the reference lines curve.

5. Forming analytical formulae for elemental efficiency factors.

6. Forming conformal formulae for the efficiency factors of conjugations.

7. Comparing conformal and elemental efficiency factors.

8. Analysis of research results and formulation of conclusions.

\section{The research methodology}

The objects of research are model hinges of borated pins and bushings of hydraulic excavator attachments $[9,10]$. Normalized systems of relative reference lines (tp) and convergences $(\varepsilon)$ were constructed using profilograms of worn surfaces [7] (see Figs. 1 $4)$.

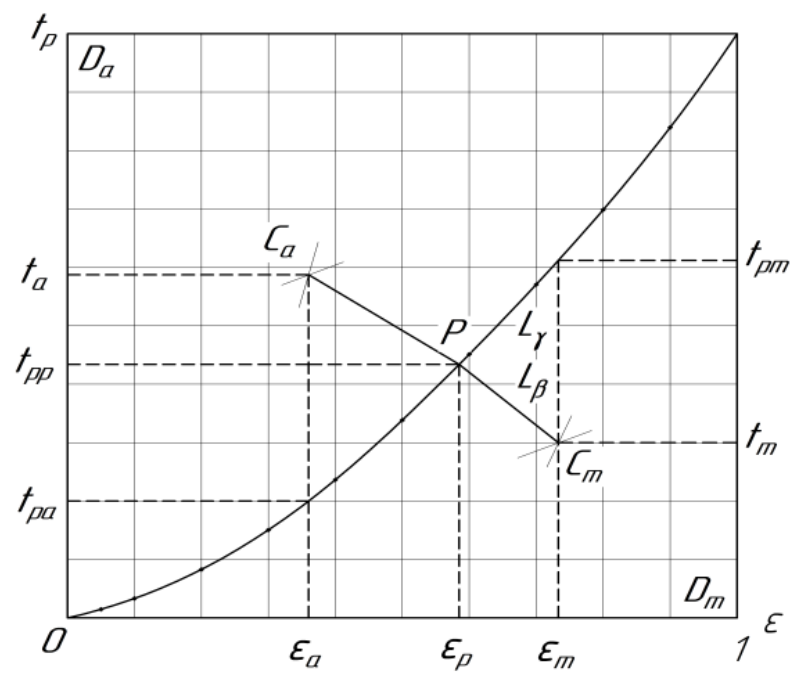

Fig. 1. (tp) and convergences $(\varepsilon) \mathrm{P} 1.1$

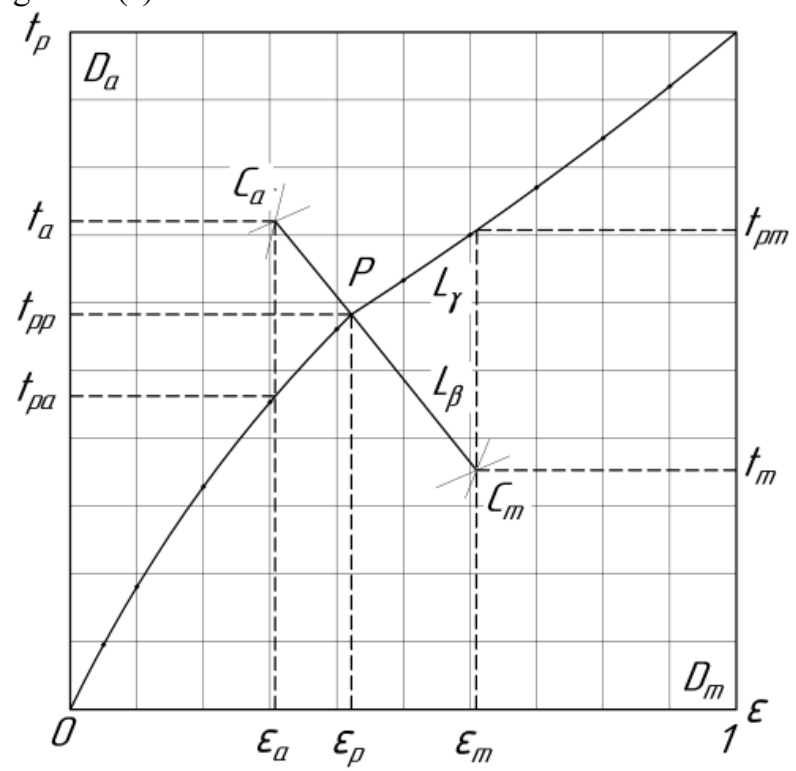

Fig. 2. (tp) and convergences $(\varepsilon) \mathrm{P} 1.2$ 


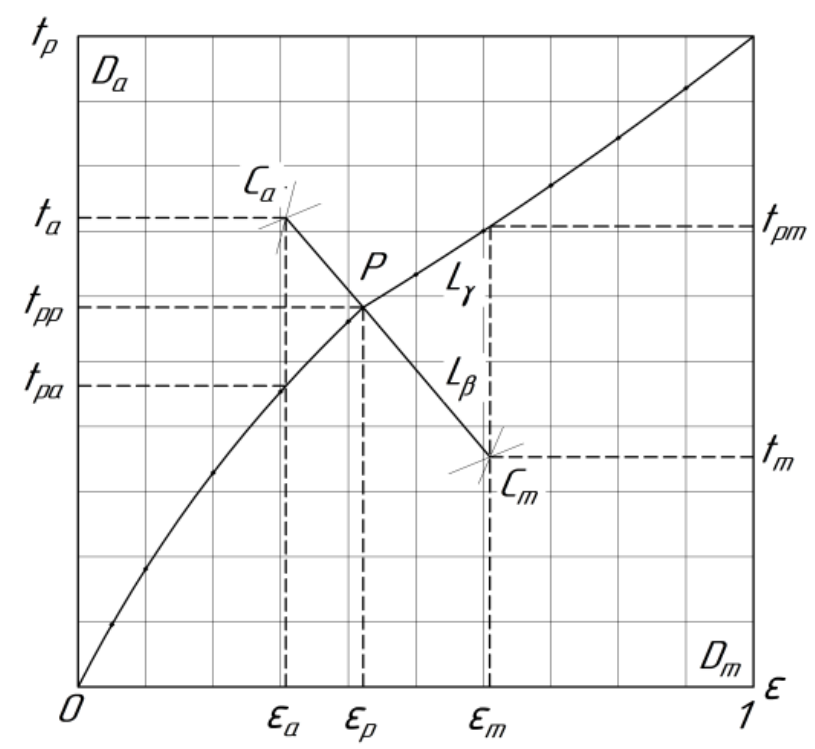

Fig. 3. (tp) and convergences $(\varepsilon) \mathrm{P} 2.4$

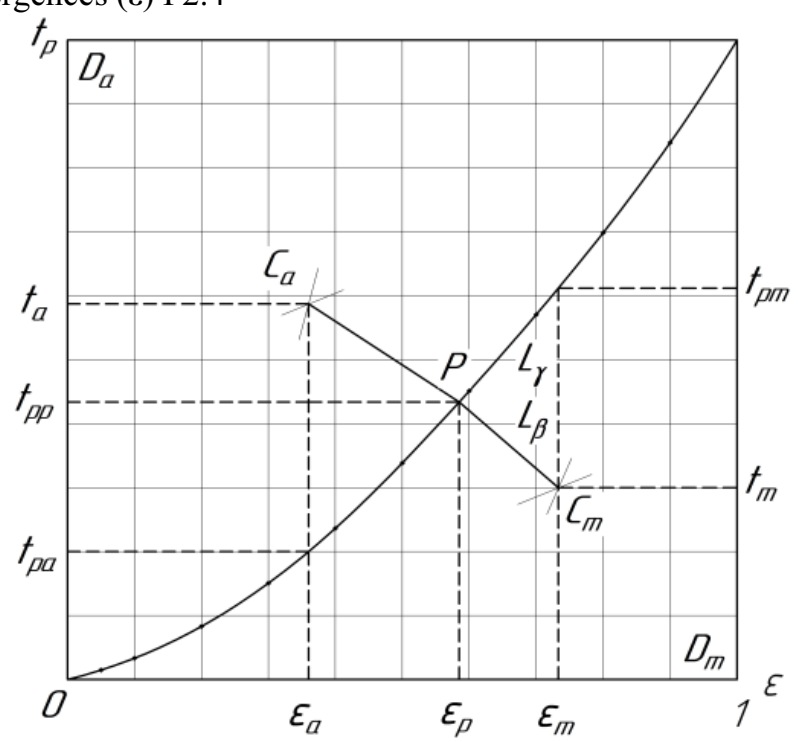

Fig. 4. (tp) and convergences $(\varepsilon) \mathrm{V} 4$

\section{Normalized systems of relative reference lines (tp) and convergences}

The initial microrelief parameters are partial values of microwear, Da and micromaterial, $\mathrm{Dm}$, determined from the ratios

$$
\mathrm{D}_{\mathrm{a}}=\mathrm{C}_{\mathrm{a}} \mathrm{P} / \mathrm{C}_{\mathrm{a}} \mathrm{C}_{\mathrm{m}}, \mathrm{D}_{\mathrm{m}}=\mathrm{C}_{\mathrm{m}} \mathrm{P} / \mathrm{C}_{\mathrm{a}} \mathrm{C}_{\mathrm{m}}
$$

where $C_{a} C_{m}$ is the relative center-to-center distance (bicentroid ${ }^{L_{\beta}}$ ) of the partial values $\mathrm{D}_{\mathrm{a}}$ and $\mathrm{D}_{\mathrm{m}} ; C_{a} P$ and $C_{m} P$ are approach and addendum components of the bicentroids $L_{\beta}$; P is the system pole; $\mathrm{D}_{\mathrm{a}}+\mathrm{D}_{\mathrm{m}}=1,0$.

The sliding friction coefficient of parts is determined by the formula 


$$
\mathrm{f}=\left(1-\mathrm{D}_{\mathrm{a}}\right)^{\frac{1}{\mathrm{Da}_{\mathrm{a}}}}=\mathrm{D}_{\mathrm{m}}^{\frac{1}{\mathrm{D}_{\mathrm{a}}}}
$$

The relative length of the reference lines curve (hypsogram ${ }^{L_{\gamma}}$ ) is estimated by the following dependence

$$
\mathrm{L}_{\gamma}=1.4142\left(\mathrm{D}_{\max } / \mathrm{D}_{\min }\right)^{\mathrm{D}_{\mathrm{a}} \cdot \mathrm{D}_{\mathrm{m}}}
$$

where $\mathrm{D}_{\max }=\mathrm{D}_{\mathrm{a}}$ at $\mathrm{D}_{\mathrm{a}}>\mathrm{D}_{\mathrm{m}}, \mathrm{D}_{\min }=\mathrm{D}_{\mathrm{a}}$ at $\mathrm{D}_{\mathrm{a}}<\mathrm{D}_{\mathrm{m}}$.

Elemental efficiency factors $(\eta)$ are determined by the formula

$$
\eta_{1}=1 /\left(1+2 f L_{\gamma} / t_{p p}\right) \text {, }
$$

where $t_{p p}$ is the relative reference line at polar convergence ${ }^{\varepsilon_{p}}$ (see Figs. 1-4).

Conformal efficiency factors are formed as follows:

$$
\begin{aligned}
& \eta_{2}=1-\left[0,25\left(f_{1}+f_{2}\right)\left(L_{1}+L_{2}\right)\right]^{0,5}, \\
& \eta_{3}=1-\left[0,5\left(f_{1} \cdot L_{1}+f_{2} \cdot L_{2}\right)\right]^{0,5},
\end{aligned}
$$

where $f_{1}, f_{2} ; L_{1}, L_{2}$ are the coefficients of friction and dimensions of the

\begin{tabular}{|c|c|c|c|c|c|c|c|c|c|c|}
\hline Part & $D_{\mathrm{a}}$ & $t_{\mathrm{pp}}$ & $\boldsymbol{L}_{\gamma}$ & $\bar{f}$ & $\begin{array}{l}\eta_{1}, \\
\%\end{array}$ & $\begin{array}{l}\eta_{2}, \\
\%\end{array}$ & $\begin{array}{l}\eta_{3}, \\
\%\end{array}$ & $\begin{array}{c}\Delta_{21}, \\
\%\end{array}$ & $\begin{array}{c}\Delta_{31}, \\
\%\end{array}$ & $\bar{\eta}_{1}, \%$ \\
\hline P1.1 & 0.613 & 0.430 & 1.42 & 0.222 & 40.5 & \multirow{2}{*}{37.8} & \multirow{2}{*}{38.7} & \multirow{2}{*}{8.6} & \multirow{2}{*}{6.4} & \multirow{2}{*}{41.35} \\
\hline V1 & 0.391 & 0.680 & 1.52 & 0.307 & 42.2 & & & & & \\
\hline P1.2 & 0.489 & 0.505 & 1.42 & 0.253 & 41.3 & \multirow[b]{2}{*}{39.1} & \multirow{2}{*}{39.1} & \multirow{2}{*}{5.1} & \multirow{2}{*}{51} & \multirow{2}{*}{41.2} \\
\hline $\mathrm{V} 2$ & 0.375 & 0.590 & 1.48 & 0.286 & 41.1 & & & & & \\
\hline P2.3 & 0.427 & 0.560 & 1.42 & 0.271 & 42.1 & \multirow{2}{*}{43.4} & \multirow{2}{*}{43.5} & \multirow{2}{*}{3.7} & \multirow{2}{*}{3.9} & \multirow{2}{*}{41.85} \\
\hline V3P2.4 & 0.263 & 0.690 & 1.55 & 0.313 & 41.6 & & & & & \\
\hline P2.4 & 0.549 & 0.480 & 1.42 & 0.234 & 41.9 & \multirow[b]{2}{*}{39.1} & \multirow{2}{*}{39.3} & \multirow{2}{*}{2.1} & \multirow{2}{*}{1.6} & \multirow{2}{*}{39.95} \\
\hline V4 & 0.310 & 0.555 & 1.50 & 0.302 & 38.0 & & & & & \\
\hline P3.5 & 0.417 & 0.565 & 1.48 & 0.274 & 41.0 & \multirow[b]{2}{*}{35.0} & \multirow[b]{2}{*}{35.0} & \multirow{2}{*}{15.0} & \multirow[b]{2}{*}{15.0} & \multirow{2}{*}{41.2} \\
\hline V5 & 0.346 & 0.620 & 1.50 & 0.293 & 41.4 & & & & & \\
\hline P3.6 & 0.598 & 0.440 & 1.50 & 0.218 & 40.2 & \multirow{2}{*}{38.8} & \multirow{2}{*}{38.8} & \multirow{2}{*}{5.4} & \multirow{2}{*}{5.4} & \multirow{2}{*}{41.0} \\
\hline V6 & 0.368 & 0.605 & 1.47 & 0.287 & 41.8 & & & & & \\
\hline P4.7 & 0.433 & 0.555 & 1.45 & 0.270 & 41.5 & \multirow{2}{*}{36.9} & \multirow{2}{*}{36.9} & \multirow{2}{*}{11.7} & \multirow{2}{*}{11.7} & \multirow{2}{*}{41.8} \\
\hline V7 & 0.374 & 0.590 & 1.45 & 0.280 & 42.1 & & & & & \\
\hline P4.8 & 0.0537 & 0.470 & 1.44 & 0.238 & 40.7 & 376 & & & & \\
\hline V8 & 0.350 & 0.610 & 1.50 & 0.292 & 41.0 & $3 / .6$ & 31.5 & 8.0 & 8.2 & \\
\hline
\end{tabular}
reference line curves of the pins and bushings, respectively.

The research results.

Table 1 shows calculation results by the dependencies (4), (5), and (6).

Table 1. Parameters of borated pins and bushings of hinges

Based on the results of Table 1, the following can be concluded.

1. The efficiency factors for pins and bushings obtained from the dependence (4) are, respectively, within virtually the same limits: $\eta_{1}=40,2-42,1$ and $\eta_{1}=38,0-42,2 \%$

2. For dry friction conditions, the average efficiency factors of the fingerbushing interfaces have limits $\bar{\eta}_{1}=40-41,8$ corresponded to efficiency factors of about $40 \%[8]$. 
3. The conformal efficiency factors calculated by the formula (5) fall within the range $\eta_{2}=35-43,4 \%$ with the mean value of $\bar{\eta}_{2}=38,5 \%$. Those calculated from the dependence (6) have the same limits $\eta_{3}=35-43,5 \%$ and the mean value of $\bar{\eta}=38,6 \%$.

4. The discrepancy between the average efficiency factors for the proposed dependencies (5) and (6) with the average value of $40.9 \%$ according to the proven formula (4) is $\Delta=5,6 \%$, which indicates the possibility of practical use of these formulae to assess the efficiency factors of hinge pairs.

Close coincidence of the efficiency values calculated by formulae (4), (5), and (6) allows the control of its determination accuracy. At the same time, the newly proposed formulae (5) and (6) seem to be more operative, as they do not require any additional definition of the pole reference line tpp in the formula (4).

The coefficient of sliding friction for fingers falls within the range of $f=0.222-0.274$ with the average value of $f=0.2475$; for bushings $f=0.280-0.313$ with the average value of $f=0.295$. The average coefficient value for all pairs of friction is $f=0.271$.

Based on this average value of the coefficient, the efficiency factor is determined by the following dependence:

$$
\eta=1-\mathrm{f} 0.382
$$

equal $\eta=0.393(39.3 \%)$.

The obtained value is apparently consistent with the above and with the efficiency factor for dry sliding friction, in particular [8].

The dependence (7) is preferable, because the relative dimension of the reference lines curve $\mathrm{L} \gamma$ is not required to determine the efficiency factor. The exponent 0.382 is the typical number of the golden ratio [10] indicating the friction and wear self-organization.

Similar dependence with the exponent of 0.618

$$
\eta=1-\mathrm{f} 0.618
$$

in the range of $0.001 \leq \mathrm{f}<0.05$ allows determination of the efficiency factor at the boundary $(\eta=60-70 \%)$ and hydrodynamic lubrication $(\eta=90-98 \%)$.

Particular value of the efficiency factor calculated from the given coefficient of sliding friction will indicate the type of friction being realized.

Forecasting of the friction type based on the known coefficient of sliding friction and the efficiency factor calculated from it is shown using the example of rubbing pairs of disc friction safety clutches [11].

Table 2 shows the initial and calculated parameters.

Table 2. Parameters of disc friction safety clutches

\begin{tabular}{|l|c|c|c|c|c|}
\hline \multicolumn{1}{|c|}{ Friction pair } & f & $\mathbf{\eta 4}, \mathbf{\%}$ & $\begin{array}{c}\text { Type of } \\
\text { friction by } \\
\boldsymbol{\eta} \mathbf{4}\end{array}$ & $\mathbf{\eta 5} \%$ & $\begin{array}{c}\text { Type of } \\
\text { friction by } \\
\boldsymbol{\eta} \mathbf{5}\end{array}$ \\
\hline $\begin{array}{l}\text { Cast iron by } \\
\text { hardened steel } \\
\text { without lubrication }\end{array}$ & $\begin{array}{c}0.15- \\
0.20 .\end{array}$ & $45.9-51.6$. & dry & - & - \\
\hline $\begin{array}{l}\text { Cast iron by cast } \\
\text { iron without } \\
\text { lubrication }\end{array}$ & $\begin{array}{l}0.15- \\
0.20 .\end{array}$ & $45.9-51.6$. & dry & - & - \\
\hline
\end{tabular}




\begin{tabular}{|l|c|c|c|c|c|}
\hline $\begin{array}{l}\text { Steel by textile } \\
\text { laminate without } \\
\text { lubrication }\end{array}$ & $\begin{array}{l}0.15- \\
0.20 .\end{array}$ & $45.9-51.6$. & dry & - & - \\
\hline $\begin{array}{l}\text { Cast iron by retinax } \\
\text { without lubrication }\end{array}$ & 0.30 & 36.9 & dry & - & - \\
\hline $\begin{array}{l}\text { Cast iron by cast } \\
\text { iron, lubricated }\end{array}$ & $\begin{array}{l}0.10- \\
0.12 .\end{array}$ & - & - & $55.5-58.5$. & boundary \\
\hline $\begin{array}{l}\text { Cast iron by bronze, } \\
\text { lubricated }\end{array}$ & $\begin{array}{l}0.05- \\
0.08 .\end{array}$ & - & - & $61.9-68.2$. & boundary \\
\hline
\end{tabular}

According to the results of Table 2, the following can be noted.

1. For dry friction of the considered pairs, the efficiency factor, when calculated by the formula (7), reaches values of $36.9-51.6 \%$; for lubricated friction, calculation by the same formula gives values $\eta=55.5-68.2 \%$, indicating the boundary friction.

2. For lubricated friction, the efficiency factor determined by the formula (8) is $73-84 \%$ that can be considered as mixed boundary-hydrodynamic friction.

3. The comparison of the efficiency factors from items 1 and 2 for lubricated friction, the values obtained by the formula (7) are more consistent with the actual friction conditions.

4. The calculation according to the formula (7) confirms the efficiency factor ranges for dry friction in the range of $37-52 \%$, and for lubricated boundary friction in the range of $56-68 \%$.

\section{Analysis of the research results}

The analysis of the results obtained leads to the following main conclusions.

1. Part-wise determination of the efficiency for pins and bushings according to the dependence (4) gives close values, $\eta P=40.2-42.1 \%$ and $\eta 8=38.0-42.2 \%$, respectively, consistent with the limiting value of $40 \%$ for dry sliding friction [8]. Conformal efficiency factors for finger - bushing friction pairs calculated by the formulae (5) and (6) have the values $\eta=35.0-43.4 \%$ and $\eta=35.0-43.5 \%$ with the average values of $38.5 \%$ and $38.6 \%$;

2. The discrepancy between the average detail and conformal efficiency factors is insignificant and amounts to $5.6 \%$.

3. If it is impossible to profile the worn surfaces of one of the mating parts and to assess the conformal efficiency factor, the efficiency factor of the friction pair can be obtained by a part-wise method according to the dependence (4).

4. This is also possible when using formulae (7) and (8), depending on the range of determination of the sliding friction coefficient $0.05<\mathrm{f}<0.35$ and $0.001 \leq \mathrm{f}<0.05$ [8].

5. The efficiency factors obtained by the formulae (4) - (7) ranged within $37-52 \%$ and $56-68 \%$ characterize the modes of dry and boundary friction, respectively; the formula (8) reflects hydrodynamic (at $\eta=90-98 \%$ ) and mixed boundaryhydrodynamic mode $(0.70<\eta<90 \%)$. The above friction pairs do not operate in the latest modes. 


\section{Conclusion}

The investigated part-wise and conformal (adaptive) methods for determining efficiency factors are quite satisfactorily consistent with each other in assessing the efficiency factor and typical friction and lubrication modes. The use of various initial parameters of the microrelief of friction surfaces with their close numerical correspondence for determining the efficiency factor may indicate the friction and wear self-organization.

\section{References}

1. Fundamentals of Tribology (Friction, Wear, Lubrication). A.V. Chichinadze, E.A. Braun, N.A. Bush et al. - M.: Mashinostroenie. 2001 - 664 P. (in Russian)

2. Garkunov D.N. Triboengineering (Wear and Wearlessness). M.: Publishing House of RSAU, 2001. - 616 P. (in Russian)

3. Kragelsky I.V., Dobychin M.N., and Kombalov V.S. Fundamentals of Friction and Wear Calculations. M.: Mashinostroenie. 1977 - 526 P. (in Russian)

4. Gustov Yu.I. and Tsipursky I.L. Investigation of the performance of the road milling cutter blades with articulated blades, Privody i Komponenty Mashin, 2019, No. 1-2, PP. 24-27. (in Russian)

5. Gustov Yu.I., Yushkov A.A., and Subbotina D.S. Reduced radii of partial values and coefficients of efficiency of tribosystems of construction equipment, Mekhanizatsiya Stroitelstva, Vol. 78(9), 2017 — PP. 44-48. (in Russian)

6. Gustov D.Yu., Gustov Yu.I., and Yushkov A.A. Abrasive wear mechanisms and efficiency of construction equipment, Mekhanizatsiya Stroitelstva, No. 9, 2016 — PP. 50-54. (in Russian)

7. Gustov Yu.I. and Shishkov P.E. Investigation of the tribomechanical parameters of the friction surfaces of the hydraulic excavator working equipment, Pod'emnoTransportnoe Delo, No. 6, 2019 - PP. 2-5. (in Russian)

8. Czichos H. System Analysis in Triboengineering. - M.: MIR, 1982 - 351 P. (in Russian)

9. Drozdov A.N. Construction Machinery and Equipment. M.: Publishing Center «Akademia», 2012 - 448 P. (in Russian)

10. Korobko V.I. Golden Ratio and Problems of Harmony ***** - M .: Publishing House ASV of the CIS countries, 1998 - 373 P. (in Russian)

11. Ryakhovsky O.A. and Ivanov S.S. Handbook of Couplings. L.: POLITEKHNIKA, 1991 - 384 P. (in Russian) 